\title{
A FORMAÇÃO DE PROFESSORES NA NOVA ORDEM DE DISCURSO DA EDUCAÇÃO BRASILEIRA
}

\section{Alexandre Costa}

\begin{abstract}
:
In this paper, we are concerned with the new educational order of discourse in Brazil and their consequences to teacher education. The technocratic reorganization of this macro institutional social field by the new liberal government in the past decade has caused a strategic control of political and pedagogical school resources with their submission to specific financial chains. It is mainly a question of reordering the previous intertextual references of school practices, but it is also a matter of rebuilding teachers' identities by new genres and discourses.
\end{abstract}

Key words: Order of discourse; intertextuality; teacher education.

Fora de cogitação, entretanto, está o fato de se poder descrever, sem limites, todas as relações que possam assim aparecer. É preciso, numa primeira aproximação, aceitar um recorte provisório: uma região inicial que a análise revolucionará reorganizará se for necessário. Michel Foucault, Arqueologia do saber, p. 33.

\section{ORDEM E CONFLITO}

O objetivo deste trabalho é apontar indicialmente ${ }^{1}$ quatro macro-processos constitutivos da nova ordem discursiva da Educação brasileira, de modo a fundamentar a hipótese de que a formação de professores em

\footnotetext{
${ }^{1}$ Dada a complexidade e a magnitude dos processos referidos, uma análise com as dimensões deste artigo não poderia ser mais do que indicativa; trata-se apenas de apresentá-los suficientemente, situá-los como um recorte possível e legítimo.
} 
nosso país passa a refletir o conflito de duas demandas históricas, terminando por submeter uma à outra: a adequação do trabalho escolar à reorganização da atividade econômica superpõe-se à qualificação política das praticas educativas.

O exame da relação intertextual de leis e programas que constituem a nova ordem permite supor que a formação para o trabalho, como 'atividade de ensino', e pelo trabalho, como 'formação em serviço', constrói-se em permanente conflito com a demanda de 'gestão democrática', seja como gerenciamento de recursos financeiros da escola, seja como elaboração de propostas político-pedagógicas. Nesse sentido, o trabalho do professor estaria no centro de contendas e paradoxos do viés periférico da modernidade tardia, no contexto da Educação brasileira.

Teoricamente, a noção de "ordem de discurso" é usada pelo viés descritivo/interpretativo que Chouliaraki e Fairclough (1999: 114) fazem do conceito epistemológico de Foucault (1996), originariamente gerado num contraste às ordens do significante e do desejo, e da categoria de 'campo'2 de Bourdieu (1997):

Uma ordem de discurso é uma articulação socialmente estruturada de práticas discursivas (tanto gêneros como discursos) que constitui a face discursiva da ordenação social de um campo social [...] a lógica discursivoorganizacional de um campo.

Empiricamente, diz respeito à sua utilização no mapeamento de estruturas discursivas e seu relacionamento com as conjunturas, práticas, eventos e seus sentidos, na conformação desse panorama. Sem perder de vista a advertência do filósofo francês à abordagem arqueológica, na epígrafe, analisa-se um determinado percurso intertextual que produz

\footnotetext{
${ }^{2}$ Para Bourdieu (1997: 32), um campo é identificável pela especificação de "um princípio de diferenciação que permite reengendrar teoricamente o espaço social empiricamente observado". Por espaço social entende "estruturas de diferenças" perceptíveis pela construção do "princípio gerador" que as funda no "plano da objetividade"e que "não é senão a estrutura da distribuição das formas de poder ou das espécies de capital que são eficientes no universo social considerado". De um modo geral, a noção de "capital” está ligada a recursos culturais, econômicos e sociais, de valor relativo, de acordo com as estruturas estudadas.
} 
sucessivas especificações de paradigmas e de uma certa regulação/normalização da atividade discursiva no âmbito da Educação e da formação de professores.

A referência a uma nova ordem de discurso implica, portanto, a recuperação da cadeia intertextual que a forma, seja em nível manifesto, seja em nível constitutivo. Por intertextualidade manifesta, entende-se a recuperação explícita de textos anteriores; nesse viés, destaca-se a representação do discurso ou modo pelo qual trechos de textos anteriores são repetidos ou citados pelos subseqüentes. Já no caso da intertextualidade constitutiva, ou interdiscursividade, mais do que a presença de textos anteriores, trata-se de uma configuração de textos subseqüentes por elementos de uma ou de várias ordens de discurso, com especial atenção às categorias de gênero e de discurso. Gêneros são os conjuntos de convenções relativamente estáveis que são associados a determinados tipos de atividade; são tipos de texto, com seus registros, estilos e modos retóricos específicos. Já discursos são modos particulares de construir uma determinada área de conhecimento e seus tópicos (Fairclough, 1992; Chouliaraki e Faiclough, 1999).

No caso dos dados analisados, por exemplo, nota-se a presença de um discurso tecnocrático associado a gêneros como exames de avaliação da produtividade do sistema educacional. Nesse sentido, tanto a forma de representação da área quanto os instrumentos discursivos que orientam as práticas de professores e alunos são alterados. É pela consideração desse processo cumulativo e qualitativo de transformações das práticas discursivas que se pode fazer referência a uma nova ordem.

\section{'CortaR' a ORdem}

Há muitas entradas possíveis para a análise da nova ordem, mas talvez nenhuma seja tão produtiva como a Lei de Diretrizes e Bases da Educação Nacional (LDB), de 1996, onde já é possível verificar a condensação de certas concepções fundamentais. Apesar de apresentar um conceito bastante abrangente de “educação', referente a todo tecido social e suas práticas, a lei direciona-se ao âmbito escolar. Nesta redução, dois 
aspectos da definição merecem reiteradas ressalvas no texto: de um lado, a vinculação da educação escolar à "qualificação para o trabalho" e, de outro, seu direcionamento ao "preparo para a cidadania", conforme se pode verificar no trecho citado a seguir (grifos nossos):

\section{Título I}

\section{Da Educação}

Art. $1^{\text {o }}$ A educação abrange os processos formativos que se desenvolvem na vida familiar, na convivência humana, no trabalho, nas instituições de ensino e pesquisa, nos movimentos sociais e organizações da sociedade civil e nas manifestações culturais.

$\S 1^{\text {o }}$ Esta Lei disciplina a educação escolar, que se desenvolve, predominantemente, por meio do ensino, em instituições próprias.

$\S 2^{\circ}$ A educação escolar deverá vincular-se ao mundo do trabalho e à prática social.

\section{Título II}

\section{Dos Princípios e Fins da Educação Nacional}

Art. $2^{\circ}$ A educação, dever da família e do Estado, inspirada nos princípios de liberdade e nos ideais de solidariedade humana, tem por finalidade o pleno desenvolvimento do educando, seu preparo para o exercício da cidadania e sua qualificação para o trabalho.

Art. $3^{\circ} \mathrm{O}$ ensino será ministrado com base nos seguintes princípios:

I - igualdade de condições para o acesso e permanência na escola;

II -liberdade de aprender, ensinar, pesquisar e divulgar a cultura, o pensamento, a arte e o saber;

III - pluralismo de idéias e de concepções pedagógicas;

IV - respeito à liberdade e apreço à tolerância;

V - coexistência de instituições públicas e privadas de ensino;

VI - gratuidade do ensino público em estabelecimentos oficiais;

VII - valorização do profissional da educação escolar,

VIII - gestão democrática do ensino público, na forma desta Lei e da legislação dos sistemas de ensino;

IX - garantia de padrão de qualidade;

X - valorização da experiência extra-escolar;

XI - vinculação entre a educação escolar, o trabalho e as práticas sociais. 
A ênfase recebida por esses tópicos será uma constante nos desdobramentos mais estruturantes da nova ordem, com o privilégio da perspectiva de qualificação para o trabalho ${ }^{3}$. No entanto, não se deve perder de vista que a nova ordem é atravessada por um discurso de promoção da cidadania e que, portanto, o evidente "desequilíbrio" lógico da equiparação das propostas de valorização da "experiência extra-escolar" e "do profissional da Educação" talvez não seja realmente algum tipo de incoerência, mas apenas índice do discurso hegemônico.

De fato, esses dois tipos de especificação dos propósitos da atividade educativa já apareciam na Constituição de 1988 e na LDB de 1971. No texto mais antigo, no entanto, não havia, entre os sentidos fundamentais da lei, a referência à "valorização do profissional da educação", como encontraremos nos textos seguintes (grifos nossos).

\section{Capítulo III Da Educação, da Cultura e do Desporto Seção I Da Educação}

Art.205 A educação, direito de todos e dever do Estado e da família, será promovida e incentivada com a colaboração da sociedade, visando ao pleno desenvolvimento da pessoa, seu preparo para o exercício da cidadania e sua qualificação para o trabalho.

Art 2060 ensino será ministrado com base nos seguintes princípios

I - igualdade de condições para o acesso e permanência na escola;

II - liberdade de aprender, ensinar, pesquisar e divulgar o pensamento, a arte e o saber;

III - pluralismo de idéias e de concepções pedagógicas e coexistência de instituições publicas e privadas de ensino;

IV - gratuidade do ensino publico em estabelecimentos oficiais;

V - valorização dos profissionais do ensino, garantindo, na forma da lei, planos de carreira para o magistério público, com piso salarial profissional e ingresso

\footnotetext{
${ }^{3}$ Não se trata de uma questão simples, haja vista que o trabalho é uma prática social e participa da cidadania; a equiparação desses conceitos ou a separação de "trabalho" e "cidadania" é uma pista sobre a orientação geral da nova ordenação, na direção da separação entre economia e política.
} 
exclusivamente por concurso público de provas e títulos, assegurado regime jurídico único para todas as instituições mantidas pela União;

VI - gestão democrática do ensino publico, na forma da lei;

VII - garantia de padrão de qualidade.

Texto constitucional, de 1988

\section{CAPÍTULO I}

\section{Do Ensino de $1^{\circ}$ e $2^{\circ}$ graus}

Art. $1^{\circ} \mathrm{O}$ ensino de $1^{\circ}$ e $2^{\circ}$ graus tem por objetivo geral proporcionar ao educando a formação necessária ao desenvolvimento de suas potencialidades como elemento de auto-realização, qualificação para o trabalho e preparo para o exercício consciente da cidadania.

\section{LDB, de 1971}

Se, por um lado, e com um certo detalhismo sintático e lexical, o texto constitucional de 1988 apaga a restrição expressa pelo adjetivo 'consciente' e inverte a ordem entre 'qualificação para o trabalho' e 'preparo para o exercício da cidadania', cabe observar que a LDB de 1996 aponta a responsabilidade da educação primeiro à família e depois ao Estado. Isso que pode parecer, em princípio, uma futilidade analítica, vai mostrar-se cada vez mais consistente à medida que, pelo exame de textos subseqüentes, encontremos a ratificação intertextual de alguns desses tópicos e o apagamento de outros. No Plano Nacional de Educação (PNE), de 2001, por exemplo, a referência à "valorização do professor" recuperará a precedência da "qualificação para o trabalho"; a formação inicial e continuada do professor passa a ser o primeiro elemento de especificação dessa demanda e, assim, recupera, em alguma medida, um certo sentido presente na LDB do regime autoritário, como se pode ver no extrato a seguir ${ }^{4}$.

4. Valorização dos profissionais da educação. Particular atenção deverá ser dada à formação inicial e continuada, em especial dos professores. Faz parte dessa valorização a garantia das condições adequadas de trabalho, entre

\footnotetext{
${ }^{4}$ Lei ${ }^{\circ} .10 .172$, de 9 de janeiro de 2001.
} 
elas o tempo para estudo e preparação das aulas, salário digno, com piso salarial e carreira de magistério.

Ainda que, no nível da intertextualidade manifesta, faça-se notar uma certa instabilidade conceitual nesses documentos do período de 1988 a 2001, será pela análise dos processos de intertextualidade constitutiva que se poderá referendar a hipótese sugerida acima, especialmente, pelo exame da relação entre a disposição dos níveis de atuação do Estado e a especificação das práticas escolares. A nova LDB, com a indicação da função "redistributiva e supletiva" da União, abrirá espaço para que o Estado, por meio da justaposição de mecanismos de financiamento à implementação de programas e projetos, retire, em grande medida, a autonomia financeira e político-pedagógica das escolas. No desdobramento dessa função, e depois de muitos níveis de especificação, haverá conseqüências muito importantes para a formação do(a) professor(a) (grifos nossos).

Art. $8^{\circ}$ A União, os Estados, o Distrito Federal e os Municípios organizarão, em regime de colaboração, os respectivos sistemas de ensino.

$\S 1^{\text {o }}$ Caberá à União a coordenação da política nacional de educação, articulando os diferentes níveis e sistemas e exercendo função normativa, redistributiva e supletiva em relação às demais instâncias educacionais. [...] Art. $9^{\circ}$ A União incumbir-se-á de:

I - elaborar o Plano Nacional de Educação, em colaboração com os Estados, o Distrito Federal e os Municípios;

[...]

III - prestar assistência técnica e financeira aos Estados, ao Distrito Federal e aos Municípios para o desenvolvimento de seus sistemas de ensino e o atendimento prioritário à escolaridade obrigatória, exercendo sua função redistributiva e supletiva;

IV - estabelecer, em colaboração com os Estados, o Distrito Federal e os Municípios, competências e diretrizes para a educação infantil, o ensino fundamental e o ensino médio, que nortearão os currículos e seus conteúdos mínimos, de modo a assegurar formação básica comum;

V - coletar, analisar e disseminar informações sobre a educação;

VI - assegurar processo nacional de avaliação do rendimento escolar no ensino fundamental, médio e superior, em colaboração com os sistemas de ensino, objetivando a definição de prioridades e a melhoria da qualidade do ensino; 


\section{[...]}

$\S 1^{\circ}$. Na estrutura educacional, haverá um Conselho Nacional de Educação, com funções normativas e de supervisão e atividade permanente, criado por lei.

A simultânea parametrização curricular e avaliativa do sistema educacional, que se desenha nos artigos apresentados, está relacionada à reorganização de campos institucionais como o Conselho Nacional de Educação (CNE) e o Instituto Nacional de Estudos e Pesquisas Educacionais Anísio Teixeira (INEP), os quais, apesar de anteriores à LDB, são consecutivamente adaptados à nova conjuntura. Essas instituições, somadas à reprodução nos níveis estadual e municipal das demandas referidas, prevista na Lei, formarão um contraponto estrutural ao estabelecimento da autonomia financeira e político-pedagógica das escolas, também previsto no texto legal. Vejam-se os artigos seguintes (grifos nossos).

Art. 12. Os estabelecimentos de ensino, respeitadas as normas comuns e as do seu sistema de ensino, terão a incumbência de:

I - elaborar e executar sua proposta pedagógica;

II - administrar seu pessoal e seus recursos materiais e financeiros;

$[\ldots]$

VI - articular-se com as famílias e a comunidade, criando processos de integração da sociedade com a escola;

VII - informar os pais e responsáveis sobre a freqüência e o rendimento dos alunos, bem como sobre a execução de sua proposta pedagógica.

Art. 13. Os docentes incumbir-se-ão de:

I - participar da elaboração da proposta pedagógica do estabelecimento de ensino; II -elaborar e cumprir plano de trabalho, segundo a proposta pedagógica do estabelecimento de ensino;

$[\ldots]$

Art. 14. Os sistemas de ensino definirão as normas da gestão democrática do ensino público na educação básica, de acordo com as suas peculiaridades e conforme os seguintes princípios: 
I - participação dos profissionais da educação na elaboração do projeto pedagógico da escola;

II - participação das comunidades escolar e local em conselhos escolares ou equivalentes.

Art. 15. Os sistemas de ensino assegurarão às unidades escolares públicas de educação básica que os integram progressivos graus de autonomia pedagógica $e$ administrativa e de gestão financeira, observadas as normas gerais de direito financeiro público.

No espaço escolar, como se pode ver no trecho anterior, as concepções e princípios da LDB desdobram-se em planos de especificação como 'propostas pedagógicas' (ou 'projetos político-pedagógicos') e 'planos de trabalho' do professor, ligados à expressão da "democratização do ensino" e à identidade profissional do docente; trata-se, em princípio, da afirmação da sua competência em seu espaço institucional imediato, com um papel direto e autorizado, mediado pelos gêneros mencionados. Essa 'qualificação política' do trabalho do professor, no entanto, será relativizada pelo seu complexo relacionamento com os outros planos de especificação já comentados, formando um sistema de quatro macro-processos discursivos da nova ordem de discurso, os quais se referenciam recíproca e continuamente.

\section{Trabalho ESCOLAR E FORMAÇÃo EM SERVIÇO NA NOVA ORDEM}

Tomando-se como foco de análise as cadeias intertextuais que, desde o aparecimento da Constituição de 1988 e da LDB de 1996, vem transformando esse imenso campo institucional a que se pode chamar de 'Educação brasileira', ou, mais especificamente, de 'Educação pública brasileira', sucessivos planos de especificação podem ser identificados a quatro macro-processos discursivos que constituem essa nova ordem:

1. REGULAMENTAÇÃO: produção de leis, pareceres, resoluções etc.

2. INSTITUCIONALIZAÇÃO: criação de campos institucionais de financiamento, supervisão e pesquisa. 
3. IMPLEMENTAÇÃO: proposição e execução de políticas educacionais por meio de planos, programas e projetos.

4. REFLEXIVIZAÇÃO: geração de informação sobre os campos institucionais e suas práticas.

No âmbito da intertextualidade manifesta, esses textos formam uma sequiência de representações de discurso que vai da regulamentação à reflexivização. No entanto, como se pôde observar na retomada que o PNE faz da questão da "valorização do professor" (ver seção anterior), vinculando-a preferencialmente à formação profissional, tópico ausente no texto anterior e em destaque no subseqüente, esta cadeia está aberta a transformações importantes.

Quanto à interdiscursividade, o fator determinante no cruzamento desses processos é a ligação da criação de fundos específicos de financiamento para determinados setores dos sistemas de ensino à parametrização curricular e avaliativa. Ainda que possam ter diferentes feições jurídicas, o importante é que seus programas, projetos e ações referem-se aos mais diversos aspectos da realidade escolar e quase sempre demandam a adaptação do trabalho docente às perspectivas político-pedagógicas da União. Tais perspectivas são fortemente instanciadas em formações profissionais específicas, provisórias e continuadas para o(a) professor(a), como demonstra a descrição do Fundo Nacional de Desenvolvimento da Educação (FNDE) apresentada pelo Ministério da Educação ${ }^{5}$ :

Trata-se de uma autarquia do Ministério da Educação que é responsável por captar e distribuir recursos financeiros a programas e projetos do Ensino Fundamental. Tais recursos são direcionados às escolas por intermédio dos Estados, Municípios e organizações não-governamentais. Os principais programas do FNDE são os seguintes: Programa Nacional de Alimentação Escolar, Programa Nacional do Livro Didático, Programa Dinheiro Direto na Escola, Programa Nacional Biblioteca na Escola, Programa Nacional de Saúde do Escolar e Programa Nacional de Transporte Escolar. A maior parte desses programas envolve formação de professores. Além disso, dispõe também de uma linha de

\footnotetext{
${ }^{5}$ Texto disponível em www.mec.gov.br.
} 
financiamento para projetos educacionais voltados para diversas áreas como, por exemplo, a aceleração da aprendizagem.

Outro exemplo é o Fundo de Fortalecimento da Escola (Fundescola), direcionado às regiões Norte, Nordeste e Centro-Oeste, que conta com recursos do governo federal e do Banco Mundial. Entre seus programas destacam-se o Plano de Desenvolvimento da Escola (PDE), o Projeto de Melhoria da Escola (PME), o Escola Ativa, o Programa Gestão da Aprendizagem Escolar (Gestar), o Programa de Apoio à Leitura e à Escrita (Gestar) e o Programa Melhoria do Rendimento Escolar. Além das vinculações imediatas de formação de professores(as) nos diversos programas e projetos desses fundos, na disputa pelo aporte de recursos as instituições escolares aderem fortemente à reprodução de paradigmas e formas de organização do trabalho escolar ditados por essas implementações de políticas públicas. Isso, em última análise, produz-se por meio da reprodução de discursos e gêneros discursivos específicos, sempre vinculados às concepções hegemônicas do governo federal.

A consequiência fundamental dessa situação é a retirada parcial da competência pressuposta do profissional da educação, base da sua autonomia político-pedagógica, sobretudo pela associação entre 'valorização' e 'formação'. Vale dizer também que, junto à associação de aporte de recursos e formação em serviço, na nova ordem reduz-se a formação inicial do docente.

Há, portanto, que se reconhecer as semelhanças entre o novo viés de formação de professores e o quadro geral de contratação e treinamento de outros profissionais, ditos "de mercado": parece haver uma colonização (Habermas, 1984) ${ }^{6}$ da ordem do discurso da Educação pelos discursos e práticas da macro conjuntura do capitalismo global. Nesse sentido, entende-se que é a "vontade de verdade” (Foucault, 1996) do discurso econômico

6 Sobretudo, pelo “deslocamento dos usos 'comunicativos' da linguagem - orientados para produzir compreensão - por usos 'estratégicos' da linguagem - orientados para o sucesso, para conseguir que as pessoas realizem coisas" (apud Fairclough, 1992: 24). E, mais do que isso, pela 'tecnologização do discurso' ou a alteração das práticas de linguagem de indivíduos e grupos orientada para a mudança social (idem, ibidem: 26-28). 
que anima o discurso político, referido sistematicamente como 'cidadania' ao longo de toda a cadeia intertextual. Em constante formação e atrelados aos discursos e gêneros dos quatro macro processos referidos, os profissionais da educação são sistematicamente construídos como 'estagiários'; esvazia-se, em grande medida, a sua posição social pela sua constante "preparação para o mundo do trabalho".

\section{REFERÊNCIAS BIBLIOGRÁFICAS}

Bourdieu, P. Razões práticas. Sobre a teoria da acção. Trad.: M. S. Pereira. Oeiras: Celta, 1997.

Brasil. Constituição da República Federativa do Brasil, promulgada em 5 de outubro de 1988. Disponível em wwro.mec.gov.br

Brasil. Lei $\mathrm{n}^{\mathrm{o}}$. 10.172, de 9 de janeiro de 2001. Aprova o Plano Nacional de Educação. Disponível em wrw.mec.gov.br

Brasil. Lei $\mathrm{n}^{\circ} .5 .692$, de 11 de agosto de 1971. Fixa diretrizes e bases para o Ensino de $1^{\circ}$. E $2^{\circ}$. Graus. Disponível em wrwr.mec.gov.br Brasil. Lei ${ }^{\circ}$. 9.394, de 20 de dezembro de 1996. Estabelece as diretrizes e bases da Educação nacional. Disponível em wrwr.mec.gov.br

Chouliaraki, L. \& Fairclough, N. Discourse in late modernity. Edinburgh University Press, 1999.

Fairclough, N. Discourse and social change. Nova York: Longman, 1992. Trad. Discurso e mudança social. Coord. trad. I. Magalhães. Brasília: Editora Universidade de Brasília, 2001.

Foucault, M. A ordem do discurso. Trad. L. F. de A. Sampaio. São Paulo: Edições Loyola, 1996.

Foucault, M. Arqueologia do saber. 6 ed. Trad. L. F. B. Neves. Rio de Janeiro: Forense Universitária, 2002. 